\title{
Efeito da inoculação de fungos micorrízicos no desenvolvimento do nabo forrageiro
}

\author{
Torres, F.E. ${ }^{\text {; }}$ Aveiro, M.C. ${ }^{\text {; }}$ Lima, K.N. ${ }^{\text {; }}$ Silva, Y.K. ${ }^{\text {; }}$ Teodoro, P.E. ${ }^{\circledR}$; Ribeiro, L.P. ${ }^{\text {; }}$; de Oliveira, E.P. ${ }^{\text {; }}$, Nicáio, J. ${ }^{\text {; }}$;
} Corrêa, C.C.G.' e Ferreira, R.S. ${ }^{1}$

'Departamento de Fitotecnia. Universidade Estadual de Mato Grosso do Sul (UEMS). Aquidauana. MS. Brasil.

\section{PALAVRAS CHAVE ADICIONAIS}

Crescimento inicial.

Espécies micorrizicas.

Brassica napus L.

\section{RESUMO}

Avaliou-se o efeito da inoculação de fungos micorrizicos arbusculares (FMA) na cultura do nabo forrageiro em casa de vegetação. Foi utilizado o delineamento inteiramente casualizado compostos por três tratamentos: não inoculado (testemunha), inoculado com Gigaspora margarita e inoculado com Glomus clarum com três repetições para cada tratamento. Os FMA influenciam diferentemente o crescimento e a produção de forragem do nabo forrageiro A inoculação com $G$. margarita proporcionou. Maior altura de plantas, massa fresca e seca de colmos, número total de folhas e volume de raízes. A inoculação com $G$. clarum proporcionou maior massa fresca e seca de folhas, demonstrando ser uma alternativa sustentável para o aumento da produção de forragem do nabo forrageiro. Recomenda-se a realização de mais pesquisas com esta cultura para que estes resultados possam ser generalizados.

\section{Effect of inoculation with mycorrhizal fungi on the development of rape}

\section{SUMMARY}

This study aimed to evaluate in a greenhouse the effect of inoculation with arbuscular mycorrhizal fungi (AMF) in the culture of the rape. A randomized design consisting of three treatments was used: uninoculated (control) inoculated with Gigaspora margarita and inoculated with Glomus clarum with three replicates for each treatment. The AMF differently influence the growth and herbage production of turnip. Inoculation with $G$. margarita increased plant height, fresh and dry weight of stems, number of leaves and root volume. Inoculation with $G$. clarum increased the fresh and dry leaves, proving to be a sustainable alternative for increasing forage production of rape. Despite the positive responses turnip inoculation with $A M F$, further research is need, so these results can be generalized.

INFORMACIÓN

Cronología del artículo.

Recibido/Received: 16.1.2014

Aceptado/Accepted: 12.1.2015

On-line: 16.3 .2015

Correspondencia a los autores/Contact e-mail:

eduteodoro@homail.com

\section{INTRODUÇÃO}

O nabo forrageiro (Brassica napus L.), é uma planta originária da Ásia Oriental e Europa, pertencente à família Brassicaceae, da ordem Caparales, de ciclo anual de inverno, herbácea, ramificada, raiz tuberosa e pivotante profunda. Apresenta tolerância a solos ácidos com alta saturação de alumínio e pode ser cultivada em sistemas conservacionistas ou convencionais, sendo muito empregada para adubação verde, rotação de cultura e produção de biodiesel (Derpsch e Calegari, 1992).

Atualmente, esta cultura tem sido muito empregada nos sistemas mais conservacionistas do solo, devido a sua alta capacidade de ciclagem de nutrientes como nitrogênio e fósforo além de sua grande produção de massa verde (Ohland et al., 2005). Uma alternativa para o uso desta espécie é a suplementação de bovinos em pastagem, sendo recomendada principalmente para solos ácidos e degradados devido ao seu alto teor de proteína e degrabilidade ruminal da matéria seca (Melo et al., 2008).

De acordo com Allen (1991), o nabo forrageiro é classificado como uma planta não microtrófica (nunca formam micorriza). Contrastando esta afirmação, uma pesquisa realizada por Gomide et al. (2009) utilizando o nabo forrageiro como tratamento controle, demonstrou interações entre esta cultura e os fungos micorrizicos arbusculares (FMA) inoculados.

Os FMA penetram nas raízes secundárias pelo micélio interno do córtex, formando um manto de hifas ao redor das raízes. Esses fungos colonizam a maioria das espécies vegetais, tendo grande importância para as regiões tropicais, propiciando uma maior capacidade de competição em solos de baixa fertilidade e favorecendo a sobrevivência dessas plantas como forrageiras (Gomide et al., 2009).

Nesse contexto, o presente trabalho teve como objetivo avaliar o efeito da inoculação de fungos mico- 
rrizicos sobre características agronômicas e produção de forragem da cultura do nabo forrageiro (Brassica napus L.).

\section{MATERIAL E MÉTODOS}

O experimento foi conduzido em casa de vegetação na Universidade Estadual de Mato Grosso do Sul, Unidade Universitária de Aquidauana, MS, compreendendo as seguintes coordenadas geográficas $20^{\circ}$ $27^{\prime} \mathrm{S}$ e $55^{\circ} 40^{\prime} \mathrm{W}$ com uma altitude média de $170 \mathrm{~m}$. O clima da região, segundo a classificação descrita por Köppen-Geiger é do tipo Aw com precipitação média anual de $1200 \mathrm{~mm}$ e temperaturas máximas e mínimas de 33 e $19{ }^{\circ} \mathrm{C}$, respectivamente. O solo da área é classificado como Argissolo Vermelho-Amarelo distrófico de textura arenosa, com as seguintes características na camada de 0 - 0,20 m: $\mathrm{pH}\left(\mathrm{H}_{2} \mathrm{O}\right)=6,2 ; \mathrm{Al}$ trocável $\left(\mathrm{cmol}_{\mathrm{c}}\right.$ $\left.\mathrm{dm}^{-3}\right)=0,0 ; \mathrm{Ca}+\mathrm{Mg}\left(\mathrm{cmol}_{c} \mathrm{dm}^{-3}\right)=4,31 ; \mathrm{P} \quad(\mathrm{mg}$ $\left.\mathrm{dm}^{-3}\right)=41,3 ; \mathrm{K}\left(\mathrm{cmol}_{\mathrm{c}} \mathrm{dm}^{-3}\right)=0,2$; Matéria orgânica $\left(\mathrm{g} \mathrm{dm}^{-3}\right)=19,74$; soma de bases $\left(\mathrm{cmol}_{\mathrm{c}} \mathrm{dm}^{-3}\right)=2,3$; CTC $\left(\mathrm{cmol}_{\mathrm{c}} \mathrm{dm}^{-3}\right)=5,1$.

Foi utilizado o delineamento inteiramente casualizado compostos por 3 tratamentos: (1) não inoculado (testemunha); (2) inoculado com Gigaspora margarita e (3) inoculado com Glomus clarum, com 3 repetições para cada tratamento.

A semeadura foi realizada em 15/05/2011 em vasos com capacidade de $8 \mathrm{~kg}$ utilizando $7 \mathrm{~kg}$ de substrato por vaso. Foram feitas 3 covas por vaso e semeada 3 sementes em cada uma. Foram efetuadas irrigações diárias as 08 horas da manhã com $50 \mathrm{~mm}$ de água por vaso. Os esporos foram obtidos da coleção de espécies da Embrapa Agropecuária Oeste em Dourados, isoladas das raízes das culturas de capim-braquiária e mandioca, que foram picadas e trituradas, aplicado $5 \mathrm{~g}$ de inóculo (raiz picada + esporos) por vaso. No dia 24/05/2011 foi realizado o primeiro processo de desbaste das plantas já germinadas deixando uma plântula por cova. Após 6 dias do primeiro desbaste foi realizado o ultimo desbaste deixando apenas 1 plântula por vaso, sendo a que se apresentou mais vigorosa.

Após 60 dias após a semeadura, com a planta em plena floração com auxílio de uma fita métrica, paquímetro e medidor de área foliar foram realizadas medições de altura de plantas (AP) e diâmetro do caule (DC), número de folha planta ${ }^{-1}$ (NFP). Após a coleta desses dados, as plantas foram cortadas rente ao solo, separando a raiz, caule e folha e lavadas com água corrente, sendo o volume das raízes (VR) obtido através da diferença entre o volume final de água mais raízes pelo volume inicial de água em um determinado recipiente. Cada parte foi acondicionada separadamente em um saco de papel para determinação da massa fresca das raízes, colmos e folhas (MFR, MFC e MFF, respectivamente). Posteriormente, estas partes foram secas em estufa com circulação forçada de ar à temperatura de $\pm 65^{\circ} \mathrm{C}$, até atingir peso constante para obtenção da massa seca da raiz, caule e folha (MSR, MSC e MSF, respectivamente). A relação folha colmo-1 foi obtida pelo quociente entre MSF e MSC.
Tabela I. Valores médios da altura de planta (AP), diâmetro do colmo (DC) e área foliar (AF) de nabo forrageiro sob inoculação de fungos micorrizicos arbusculares (FMA) em Aquidauana, MS (Average values of plant height (AP), stem diameter (DC) and leaf area (AF) of turnip under inoculation of mycorrhizal fungi (FMA) in Aquidauna, MS).

\begin{tabular}{lrrc}
\hline Tratamentos & $\mathrm{AP}(\mathrm{cm})$ & $\mathrm{DC}(\mathrm{cm})$ & $\mathrm{AF}\left(\mathrm{cm}^{2}\right)$ \\
\hline Testemunha & $53,33^{\mathrm{b}}$ & $1,04^{\mathrm{a}}$ & $792,20^{\mathrm{a}}$ \\
Gigaspora margarita & $73,70^{\mathrm{a}}$ & $1,06^{\mathrm{a}}$ & $963,70^{\mathrm{a}}$ \\
Glomus clarum & $38,16^{\mathrm{c}}$ & $1,10^{\mathrm{a}}$ & $996,71^{\mathrm{a}}$ \\
CV $(\%)$ & 12,76 & 13,60 & 16,93 \\
\hline
\end{tabular}

Médias seguidas por letras minúsculas iguais nas mesmas colunas não diferem entre si pelo teste de Duncan a $5 \%$ de probabilidade.

Tabela II. Valores médios de massa fresca de folha, colmo e raiz (MFF, MFC e MFR, respectivamente) de nabo forrageiro sob inoculação de fungos micorrizicos arbusculares (FMA) em Aquidauana, MS (Average values of fresh weight of leaf, stem and root (MFF, MFC and MFR, respectively) of wild rape under inoculation of mycorrhizal fungi (FMA) in Aquidauna, MS.)

\begin{tabular}{lccc}
\hline Tratamentos & MFF $(\mathrm{g})$ & MFC $(\mathrm{g})$ & MFR $(\mathrm{g})$ \\
\hline Testemunha & $36,12^{\mathrm{b}}$ & $24,66^{\mathrm{a}}$ & $2,52^{\mathrm{b}}$ \\
Gigaspora margarita & $41,93^{\mathrm{ab}}$ & $27,00^{\mathrm{a}}$ & $7,22^{\mathrm{a}}$ \\
Glomus clarum & $55,77^{\mathrm{a}}$ & $12,50^{\mathrm{b}}$ & $5,19^{\mathrm{ab}}$ \\
CV $(\%)$ & 16,15 & 16,83 & 41,77 \\
\hline
\end{tabular}

Médias seguidas por letras minúsculas iguais nas mesmas colunas não diferem entre si pelo teste de Duncan a $5 \%$ de probabilidade.

Os dados foram submetidos à análise de variância, utilizando o software estatístico Assistat (Silva e Azevedo, 2002), sendo as médias comparadas pelo teste de Duncan a $5 \%$ de probabilidade.

\section{RESULTADOS E DISCUSSÃO}

Na tabela I estão expressos os valores médios das variáveis altura de planta (AP), diâmetro do colmo (DC) e área foliar (AF) do nabo forrageiro em função da inoculação FMA, onde foram identificadas diferenças significativas $(\mathrm{p}<0,05)$ apenas para a AP. G. margarita proporcionou maior $\mathrm{AP}$ ao nabo forrageiro, enquanto G. clarum ocasionou redução no seu crescimento, o que indica que cada fungo interage com o hospedeiro de forma diferenciada.

Rocha et al. (2006) e Saggin Junior e Siqueira (1996), ao avaliarem o crescimento de mudas de cedro e cafeeiro, respectivamente, observaram que o fungo $G$. margarita proporcionou maior altura de plantas.

A ausência de significância para as variáveis diâmetro caulinar e área foliar, pode ser explicada de acordo com Carneiro et al. (2004), devido a inoculação com FMA ser mais eficiente quando aliada a aplicação de fósforo.

Na tabela II, observa-se diferença estatística $(p>0,05)$ entre os tratamentos inoculados com FMA e a testemunha para a massa fresca das folhas, colmo e raiz (MFF, MFC e MFR, respectivamente). Não verificou-se diferença entre a inoculação com G. clarum e G. margari- 
Tabela III. Valores médios de massa seca de folha, colmo e raiz (MSF, MSC e MSR, respectivamente) de nabo forrageiro sob inoculação de fungos micorrizicos arbusculares(FMA) em Aquidauana, MS (Average values of dry mass of leaf, stem and root (MSF, MSC and MSR, respectively) of turnip under inoculation with arbuscular mycorrhizal fungi (FMA) in Aquidauana, MS.).

\begin{tabular}{lccc}
\hline Tratamentos & MSF $(\mathrm{g})$ & MSC $(\mathrm{g})$ & $\mathrm{MSR}(\mathrm{g})$ \\
\hline Testemunha & $1,39^{\mathrm{c}}$ & $1,31^{\mathrm{b}}$ & $0,17^{\mathrm{b}}$ \\
Gigaspora margarita & $1,81^{\mathrm{bc}}$ & $2,12^{\mathrm{a}}$ & $0,51^{\mathrm{a}}$ \\
Glomus clarum & $2,95^{\mathrm{a}}$ & $0,74^{\mathrm{c}}$ & $0,28^{\mathrm{a}}$ \\
CV $(\%)$ & 20,28 & 21,01 & 53,16 \\
\hline
\end{tabular}

Médias seguidas por letras minúsculas iguais nas mesmas colunas não diferem entre si pelo teste de Duncan a $5 \%$ de probabilidade.

Tabela IV. Valores médios do número de folhas por plantas (NPF), relação folha/colmo (FC) e volume de raízes(VR) de nabo forrageiro sob inoculação de fungos micorrizicos arbusculares (FMA) em Aquidauana, MS (Average values for number of leaves per plant (NPF), leaf/stem ratio $(F / C)$ and root volume (VR) of turnip under inoculation of mycorrhizal fungi (FMA) in Aquidauna, MS).

\begin{tabular}{lccc}
\hline Tratamentos & NFP $\left(\mathrm{cm}^{3}\right)$ & $\mathrm{F} / \mathrm{C}\left(\mathrm{cm}^{3}\right)$ & VR $\left(\mathrm{cm}^{3}\right)$ \\
\hline Testemunha & $9,48^{\mathrm{b}}$ & $1,05^{\mathrm{b}}$ & $2,58^{\mathrm{b}}$ \\
Gigaspora margarita & $14,67^{\mathrm{a}}$ & $0,85^{\mathrm{b}}$ & $6,67^{\mathrm{a}}$ \\
Glomus clarum & $9,33^{\mathrm{b}}$ & $4,12^{\mathrm{a}}$ & $5,33^{\mathrm{ab}}$ \\
CV $(\%)$ & 17,63 & 27,98 & 37,45 \\
\hline
\end{tabular}

Médias seguidas por letras minúsculas iguais nas mesmas colunas não diferem entre si pelo teste de Duncan a $5 \%$ de probabilidade.

ta quanto as variáveis MFF e MFC, porém G. margarita ocasionou maior MFC. Estes resultados demonstram que o nabo forrageiro apresenta respostas agronômicas positivas e diferenciadas em função do FMA.

Estes dados corroboram com Freitas et al. (2004), que em pesquisa com inoculação de FMA em Mentha arvensis, obtiveram os melhores resultados para massa fresca das folhas e colmos para os tratamentos com fungos G. clarum e G. margarita, que aumentaram 207 e $198 \%$, respectivamente, em relação ao tratamento controle.

Na tabela III verificou-se eficiência do fungo G. clarum e G. margarita em aumentar a produção de folhas e colmos, respectivamente. Não foi observada diferença entre estes fungos com relação à MSR, sendo ambos superiores a testemunha. Considerando que a maior parte da proteína digestível para os animais está contida nas folhas, a inoculação com G. clarum pode ser uma alternativa sustentável para o aumento da produção de forragem do nabo forrageiro.

Carneiro et al. (2004) e Carneiro et al. (2010), pesquisando inoculação com FMA de mudas de embaúba (Cecropia sp.) e leguminosas respectivamente, verificaram que a massa seca da parte aérea não foi influenciada significativamente, porém houve incremento do parâmetro MSR em ambas as pesquisas.

Miranda et al. (2008) em pesquisa sobre seleção de FMA para amendoim forrageiro (Arachis pintoi), identi- ficaram que o tratamento com G. clarum proporcionou a maior produção de massa seca da parte aérea e das raízes, superando os tratamentos com G. margarita e de controle.

A inoculação com G. margarita e G. clarum foi eficiente para o incremento das variáveis NFP e F/C, respectivamente (tabela IV). Estas espécies proporcionaram, respectivamente, um incremento de 158 e 107 \% no VR em relação à testemunha.

Aguiar et al. (2004), estudando desenvolvimento do maracujazeiro pós-inoculação com FMA, observaram que o NFP não é influenciado por esta prática. Ferreira et al. (2013) ressaltam que uma maior relação F/C é importante quando se considera o pastejo de animais, pois nas folhas estão presentes os maiores teores de proteína bruta e nutrientes.

Segundo Glowa et al. (2003) e Sawyer et al. (2003), as hifas micorrizadas aumentam o volume radicular, permitindo melhor aproveitamento de água e nutrientes, como N, P e K, propiciando, assim, um maior crescimento inicial das plantas inoculadas com FMA em relação às não-inoculadas. Visto o elevado VR, a inoculação com FMA pode permitir o desenvolvimento e estabelecimento do nabo forrageiro, mesmo em solos pobres em nutrientes, degradados ou até mesmo durante o período seco do ano, sendo, portanto, uma prática a ser considerada para o pastejo animal.

\section{CONCLUSÕES}

Os fungos micorrízicos arbusculares influenciam diferentemente o crescimento e a produção de forragem do nabo forrageiro.

A inoculação com Gigaspora margarita proporcionou ao nabo forrageiro maior altura de plantas, massa fresca e seca de colmos, número total de folhas e volume de raízes.

A inoculação com Glomus clarum proporcionou ao nabo forrageiro maior massa fresca e seca de folhas, demonstrando ser uma alternativa sustentável para o aumento da produção de forragem do nabo forrageiro.

Apesar das respostas positivas do nabo a inoculação com fungos micorrízicos arbusculares, recomenda-se a realização de mais pesquisas com esta cultura para que estes resultados possam ser generalizados, visto que comportamento diferenciado da cultura.

\section{BIBLIOGRAFIA}

Aguiar, R.L.F.; Maia, L.C.; Salcedo, I.N. e Sampaio, E.V.S.B. 2004. Interação entre fungos micorrízicos arbusculares e fósforo no desenvolvimento da Algaroba [Prosopis juliflora(SW)DC]. Rev Arv, 28: 589-598.

Allen, M.F. 1991. The ecology of mycorrhizae. Cambridge University Press. 184 pp.

Carneiro, M.A.C.; Siqueira, J.O. e Davide, A.C. 2004. Fósforo e inoculação com fungos micorrízicos arbusculares no estabelecimento de mudas de embaúba (Cecropia pachystachya Trec). Pesq Agropec Trop, 34: 119.

Carneiro, R.F.V.; Martins, M.A.; Vasquez, H.M. e Detman, E. 2010. Doses de fósforo e inoculação micorrízica no cultivo de estilosantes em solo sob condições naturais. Arch Zootec, 59: 415-426. 
Derpsch, R. e Calegari, A. 1992. Plantas para adubação verde de inverno. IAPAR. Londrina (Circular, 73). 80 pp.

Ferreira, R.S.; Teodoro, P.E.; Silva Junior, A.C.; Silva, P.P.; Arima, G.M.; Cappi, N. and Torres, F.E. 2013. Effect of different doses of swine biofertilizer in the development and production of cultivars of Brachiaria brizantha. J Agron, 12: 53-58.

Freitas, M.S.M.; Martins, M.A. e Vieira, I.J.C. 2004. Produção e qualidade de óleos essenciais de Mentha arvensis em resposta à inoculação de fungos micorrízicos arbusculares. Pesq Agrop Bras, 39: 887-894.

Gomide, P.H.O.; Santos, J.G.D.; Siqueira, J.O. e Soares, C.R.F.F. 2009. Diversidade e função de fungos micorrízicos arbusculares em sucessão de espécies hospedeiras. Pesq Agrop Brás, 44: 1483-1490.

Glowa, K.R.; Arocena, J.M. and Massicote, H.B. 2003. Extraction of potassium and/or magnesium from selected soil minerals by Piloderma. Geomicrob J, 20: 99-111.

Hernani, L.C.; Endres, V.C.; Pitol, C. e Salton, J.C. 1995. Adubos verdes de outono/inverno no Mato Grosso do Sul. EMBRAPA-CPAO, Dourados. EMBRAPA-CPAO. Documentos, 4: $93 \mathrm{pp}$.
Mello, A. H.; Silva, E.M.R. e Saggin Júnior, O.J. 2012. Seleção de fungos micorrízicos arbusculares eficientes para promoção do crescimento da leguminosa Mimosa artemisiana. Agroecos, 4: 40-51.

Miranda, E.M.; Saggin Junior, O.J. e Silva, E.M.R. 2008. Seleção de fungos micorrízicos arbusculares para o amendoim forrageiro consorciado com braquiária. Pesq Agropec Bras, 43: 1185-1191.

Ohland, R.A.A.; Souza, L.C.F.; Hernani, L.C.; Marchetti, M.E. e Gonçalves, M.C. 2005. Culturas de cobertura do solo e adubação nitrogenada no milho em plantio direto. Cienc Agrotec, 29: 538-544.

Rocha, F.S.; Saggin Junior, O.J.; Silva, E.M.R. e Lima, W.L. 2006. Dependência e resposta de mudas de cedro a fungos micorrízicos arbusculares. Pesq Agropec Bras, 41: 77-84.

Saggin Junior, O.J. e Siqueira, J.O. 1996. Micorrizas arbusculares em cafeeiro. In: Siqueira, J.O. (Ed.). Avanços em fundamentos e aplicação de micorrizas. UFLA/DCS/DCF. Lavras. 254 pp.

Sawyer, N.A.; Chambers, S.M. and Cairney, J.W.G. 2003. Utilisation of inorganic and organic phosphorus sources by isolates of Amanita species native to temperature eastern Australia. Austr J Bot, 51: 151-158.

Silva, F.A.S. and Azevedo, C.A.V. 2002. Versão do programa computacional Assistat para o sistema operacional Windows. Rev Bras Prod Agr, 4: 71-78. 